\title{
CAS9 is a genome mutator by directly disrupting DNA-PK dependent DNA repair pathway
}

\author{
Shuxiang $\mathrm{Xu}^{1}$, Jinchul Kim ${ }^{2,3}$, Qingshuang Tang ${ }^{1}$, Qu Chen ${ }^{1,2}$, Jingfeng Liu ${ }^{1}$, Yang $\mathrm{Xu}^{1,2,3 \bowtie}$, Xuemei Fu ${ }^{2,4}$ \\ ${ }^{1}$ Cancer Research Institute, Guangdong Provincial Key Laboratory of Cancer Immunotherapy, School of Basic Medical \\ Sciences, Southern Medical University, Guangzhou 510515, China \\ 2 The Eighth Affiliated Hospital, Sun Yat-sen University, Shenzhen 518033, China \\ ${ }^{3}$ Division of Biological Sciences, University of California, San Diego, 9500 Gilman Drive, La Jolla, CA 92093, USA \\ ${ }^{4}$ Shenzhen Children's Hospital, Shenzhen 518026, China \\ $\bowtie$ Correspondence: yangxu@ucsd.edu (Y. Xu)
}

Received August 11, 2019 Accepted January 19, 2020

\begin{abstract}
With its high efficiency for site-specific genome editing and easy manipulation, the clustered regularly interspaced short palindromic repeats (CRISPR)/ CRISPR associated protein 9 (CAS9) system has become the most widely used gene editing technology in biomedical research. In addition, significant progress has been made for the clinical development of CRISPR/CAS9 based gene therapies of human diseases, several of which are entering clinical trials. Here we report that CAS9 protein can function as a genome mutator independent of any exogenous guide RNA (gRNA) in human cells, promoting genomic DNA double-stranded break (DSB) damage and genomic instability. CAS9 interacts with the KU86 subunit of the DNA-dependent protein kinase (DNA-PK) complex and disrupts the interaction between KU86 and its kinase subunit, leading to defective DNA-PK-dependent repair of DNA DSB damage via non-homologous end-joining (NHEJ) pathway. XCAS9 is a CAS9 variant with potentially higher fidelity and broader compatibility, and dCAS9 is a CAS9 variant without nuclease activity. We show that XCAS9 and dCAS9 also interact with KU86 and disrupt DNA DSB repair. Considering the critical roles of DNA-PK in maintaining genomic stability and the pleiotropic impact of DNA DSB damage responses on cellular proliferation and survival, our findings caution the interpretation of
\end{abstract}

Shuxiang Xu, Jinchul Kim, and Qingshuang Tang have contributed equally to this work. data involving CRISPR/CAS9-based gene editing and raise serious safety concerns of CRISPR/CAS9 system in clinical application.

KEYWORDS CAS9, DNA-PK, DNA double-stranded breaks, genetic instability, DNA repair

\section{INTRODUCTION}

CAS9 is a type II DNA endonuclease widely used in genome editing and epigenetic modification (Jinek et al., 2012; Cong et al., 2013; Mali et al., 2013). CAS9 can efficiently target the entire genomic DNA sequence using the Protospacer Adjacent Motif (PAM) domain and a guide RNA (gRNA) (Komor et al., 2017; Murovec et al., 2017). In addition to its extensive use in biomedical research, the clinical application of the CRISPR/CAS9 system in human therapy has been intensively investigated (Barrangou and Doudna, 2016; Dever et al., 2016; Urnov, 2018; WareJoncas et al., 2018; Zhu et al., 2019). Variants of CAS9 have also been developed for distinct biological functions and improved editing fidelity. For example, the nuclease dead-CAS9 (dCAS9) has been developed for gene activation (Gilbert et al., 2013; Maeder et al., 2013), RNA editing (Cpf1) (Zetsche et al., 2015), and some smaller editing systems (Harrington et al., 2018). However, a number of problems still challenge the broad utility of CAS9 in research and clinical application (Tan et al., 2015; Haapaniemi et al., 2018; Ihry et al., 2018). For example, recent reports indicate that the combination of CAS9 and gRNA introduces genomic DNA DSBs, leading to p53-dependent cytotoxicity of human pluripotent stem 
cells (Ihry et al., 2018). Using long-read sequencing, researchers recently show that the genome editing mediated by CRISPR/CAS9 and gRNA could lead to large DNA deletions and complex rearrangements in the genome (Guo et al., 2018; Kosicki et al., 2018; Lei et al., 2018).

DNA double-stand break (DSB) damage is the most common genomic DNA lesion during cellular proliferation and genome editing (Jackson and Bartek, 2009), which could be repaired by two pathways: the direct DNA ligation of the broken DNA ends termed NHEJ and homologous DNA template guided homologous directed repair (HDR) (Mladenov and Iliakis, 2011). Immediately after the introduction of DSB, the DNA repair pathways are activated with a large panel of proteins recruited to the site of DNA DSBs (Mladenov and Iliakis, 2011). In the context of NHEJ, Ku70/ 86 heterodimer bind to the DNA DSBs to stabilize the DNA DSB ends and then recruit DNA dependent protein kinase catalytic subunit (DNA-PKcs) to the site of DNA DSB (Davis et al., 2014). DNA-PK complex is required for NHEJ by recruiting and phosphorylating a panel of the DNA repair factors including XRCC4 to facilitate DNA DSB repair (Uematsu et al., 2007; Davis et al., 2014). We demonstrate that CAS9 can disrupt the formation of DNA-PK complex through the interaction with KU86, promoting DNA DSB damage.

\section{RESULTS AND DISCUSSION}

\section{CAS9 induces DNA DSB damage in human cells independent of gRNA}

For the clinical application of any gene editing technology, the genetically modified cells must maintain genomic stability. Because there is no reported study to investigate the impact of CAS9 on the genomic stability in the absence of gRNA, we used the doxycycline (Doxy) inducible expression system to induce the expression of CAS9 in human embryonic stem cells (hESCs). The expression of CAS9 protein in the absence of any exogenous gRNA activated DNA damage responses, including the phosphorylation of p53 at Ser15, CHK1 at Ser317, and H2AX at Ser139 (Fig. 1A). Consistent with this finding, the expression of CAS9 protein alone in hESCs was sufficient to induce the foci formation of H2AX at Ser139 ( $\mathrm{YH} 2 \mathrm{AX}$ ), a marker for DNA DSBs in the genome (Fig. 1B). We used comet assay to confirm that the expression of CAS9 protein alone in hESCs induced DNA DSB damage (Fig. 1C). Nuclear fractionation analysis indicated that CAS9 is present in both nucleus and cytoplasm (Fig. 1D). Activation of p53 in hESCs can activate apoptosis and differentiation of hESCs as previously shown (Lin et al., 2005; Song et al., 2010). The DNA DSB damage induced by CAS9 activated the expression of p53 target genes such as PUMA, p21, PERP and NOXA, leading to the cell death and differentiation of hESCs (Fig. 1E-G).
Figure 1. The expression of CAS9 alone in hESCs promotes DNA DSB damage and activates DNA damage response pathway. (A) Inducible expression of CAS9 in hESCs activated DNA damage response. Lentivirus harboring the inducible CAS9 expression cassette or control empty vector was used to transduce hESCs. The expression of CAS9 was induced with $2 \mu \mathrm{g} / \mathrm{mL}$ doxycycline (Doxy) treatment for $0,24 \mathrm{~h}$ and $48 \mathrm{~h}$. The relative levels of the phosphorylation of p53, H2AX, CHK1 were indicated at the bottom. $n=3$. Data are presented as mean value \pm SD. ${ }^{*} P<0.05,{ }^{*} P<0.01$. (B) The expression of CAS9 induced the number of the $\mathrm{YH} 2 \mathrm{AX}$ foci in hESC. hESCs with CAS9 inducible expression cassette were plated on chamber slides and treated with or without $2 \mu \mathrm{g} /$ $\mathrm{mL}$ doxycycline for 3 days. The $\mathrm{YH} 2 \mathrm{AX}$ foci were detected by a confocal microscope. Scale bar, $10 \mu \mathrm{m}$. Unpaired $\mathrm{t}$ test. $n=20$. Data are presented as mean value \pm SD. ${ }^{* \star \star} P<0.001$. (C) Detection of DNA DSB damage by Comet assay in hESCs after various treatments. CTL, hESCs with empty expression vector treated with $2 \mu \mathrm{g} / \mathrm{mL}$ doxycycline (Doxy), doxorubicin (Dox), Doxy + Dox, hESCs with CAS9 inducible expression vector were treated with $2 \mu \mathrm{g} / \mathrm{mL}$ doxycycline for three days, 0.5 $\mu \mathrm{mol} / \mathrm{L}$ Dox for $2 \mathrm{~h}, 2 \mu \mathrm{g} / \mathrm{mL}$ doxycycline for three days + $0.5 \mu \mathrm{mol} / \mathrm{L}$ Dox for $2 \mathrm{~h}$. Unpaired $t$ test. $n=20$. Data are presented as mean value \pm SD. ${ }^{* *} P<0.001$. (D) CAS9 is present in both nucleus and cytoplasm. CTL or CAS9, hESCs with lentiviral empty vector or CAS9 inducible expression cassette were treated with $2 \mu \mathrm{g} / \mathrm{mL}$ doxycycline for 3 days. Cells were fractionated into nuclear and cytoplasmic fractions, and examined for the levels of CAS9 as well as nuclear and cytoplasmic proteins histone $\mathrm{H} 3$ and a-tubulin. (E) The expression of p53 target genes in hESCs after the expression of CAS9. CTL, CAS9, hESCs with CAS9 inducible expression vector were treated with or without $2 \mu \mathrm{g} / \mathrm{mL}$ doxycycline for 3 days. $n=3$. Data are presented as mean value $\pm \mathrm{SD}$. ${ }^{*} P<0.05,{ }^{* *} P<0.01$, ${ }^{* * *} P<0.001$. (F) Cellular proliferation after the expression of CAS9 in hESCs. $n=3$. Data are presented as mean value \pm SD. ${ }^{* *} P<0.001$. (G) The impact of CAS9 expression on the pluripotency of hESCs. The pluripotency makers TRA1-60 and TRA1-81 were analyzed in hESCs with or without CAS9 expression induced by $2 \mu \mathrm{g} / \mathrm{mL}$ Doxy for 4 days.

To confirm this genome mutator function of CAS9 in mammalian cells, we employed the same CAS9 inducible expression system to express CAS9 in human induced pluripotent stem cells (hiPSCs) and human fibroblasts. Consistent with the findings in hESCs, the expression of CAS9 alone in hiPSCs and human fibroblasts was sufficient to induce DNA DSB damage and activate DNA damage responses (Figs. $2 A$ and $3 A-C$ ). Using decreasing dosages 

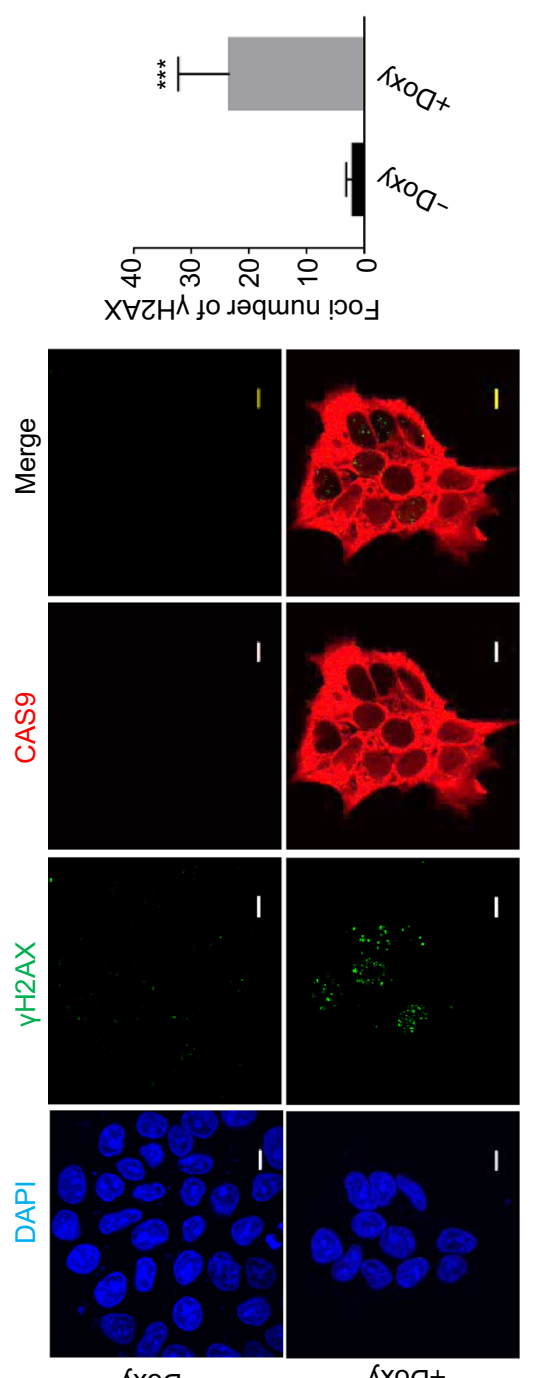

KxoO-

$\infty$

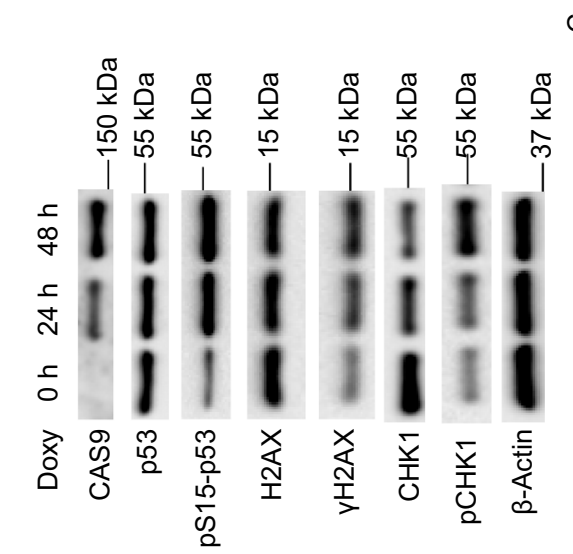

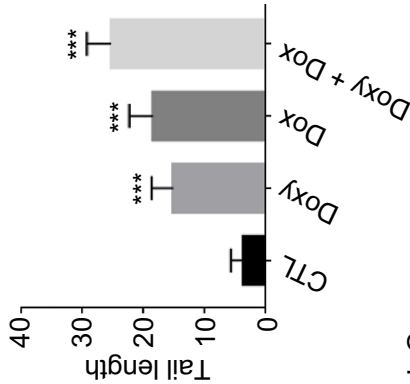
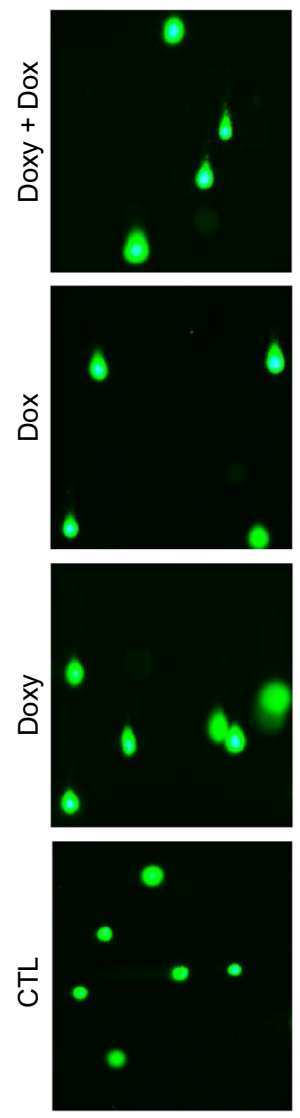

u
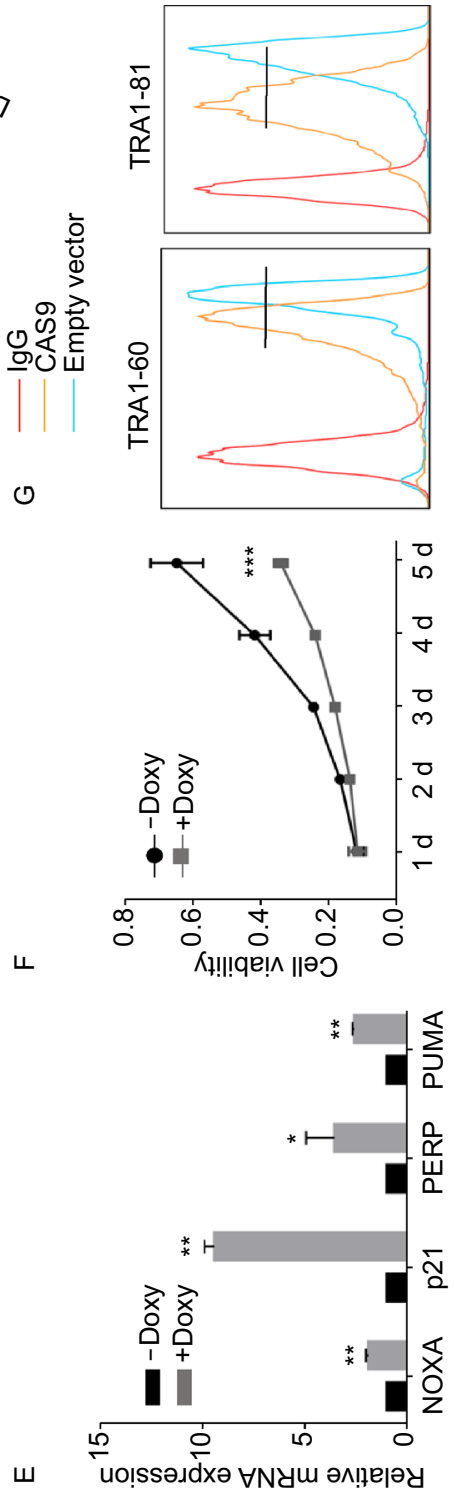

ш uo!ssəıdx $\forall$ Nyu әм!̣е|әу

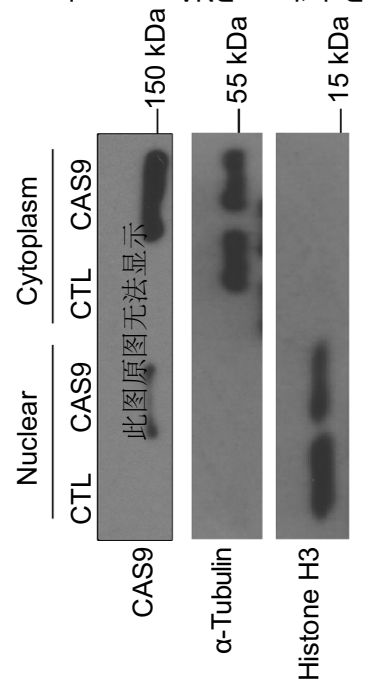


A

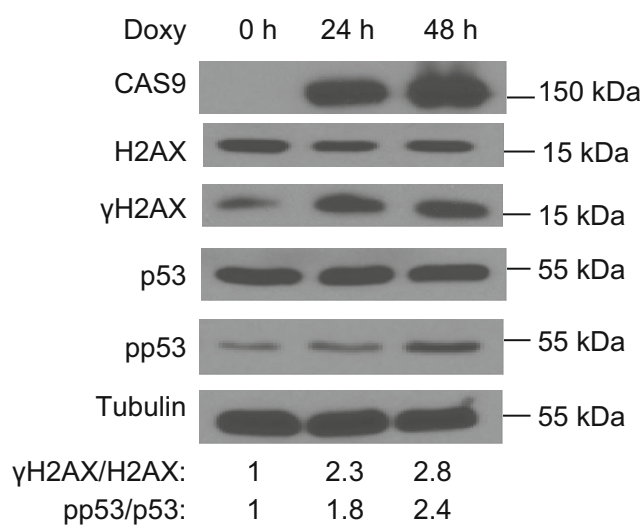

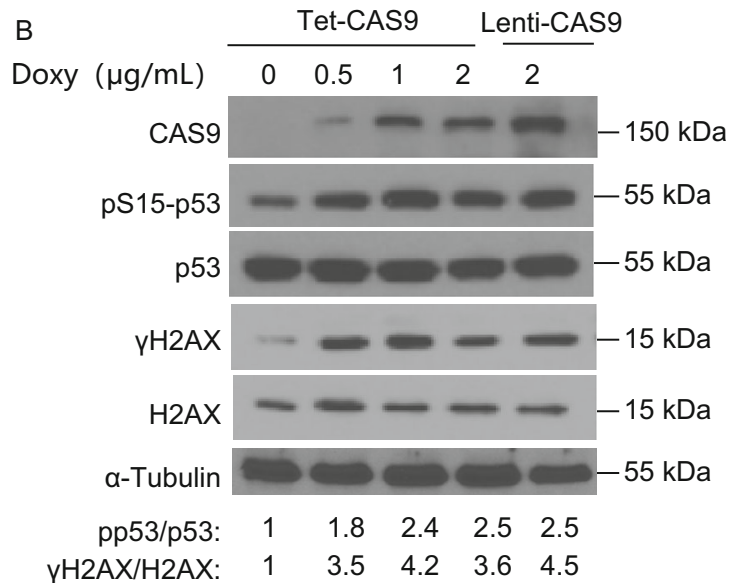

Figure 2. The expression of CAS9 in hiPSCs and hESCs promotes DNA DSB damage. (A) The inducible expression of CAS9 promotes DNA DSB damage responses in hiPSCs after $2 \mu \mathrm{g} / \mathrm{mL}$ Doxy treatment. The relative levels of the phosphorylation of p53 and $\mathrm{H} 2 \mathrm{AX}$ are indicated at the bottom. Consistent data were obtained from two independent experiments. (B) The impact of expression levels of CAS9 on DNA DSB damage in hESCs. At the same lentiviral titers, the expression levels of CAS9 in hESCs transduced by standard lentiviral vector are higher than those transduced by the inducible lentiviral vector after $2 \mu \mathrm{g} / \mathrm{mL}$ Doxy treatment. Much lower expression levels of CAS9 can also promote DNA DSB damage in hESCs after the treatment with lower dosages of Doxy. The relative levels of the phosphorylation of p53 and H2AX are indicated at the bottom.

of Doxy to induce much lower expression of CAS9, we showed that, at the expression levels much lower than those of standard lenti-viral transduction, CAS9 could still induce DNA DSB damage (Fig. 2B). Therefore, CAS9 can induce DNA DSB damage in mammalian cells independently of exogenous gRNA.

\section{CAS9 disrupts DNA-PK complex by interacting with KU86}

To elucidate the mechanism how CAS9 induces DNA DSB damage, we investigated the potential interaction between CAS9 and the components of DNA repair pathways. We discovered that CAS9 interacted with KU86, a component of DNA-PK complex essential for NHEJ pathway (Fig. 4A and 4B). The interaction between CAS9 and KU86 was further confirmed by proximity ligation assay (Fig. 4C). Using a series of deletional mutants of CAS9, we found that the PAM domain of CAS9 was involved in the interaction with KU86 and other domains of CAS9 might interfere with the interaction between the PAM domain and KU86 (Fig. 4D). In further support of this notion, the expression of the PAM domain of CAS9 reduced the interaction between CAS9 and KU86 (Fig. 4E). The expression of CAS9 disrupted the interaction between KU86 with DNA-PKcs or K70, indicating that the interaction between CAS9 and KU86 inhibited the formation of DNA-PK complex (Fig. 4F).

The formation of DNA-PK complex at the site of DNA DSB is required for repairing DNA DSB via NHEJ and maintaining genomic stability (Davis et al., 2014). Therefore, we hypothesized that CAS9 could inhibit DNA DSB repair via NHEJ pathway and induce genomic instability by disrupting the formation of DNA-PK complex. In support of this notion, the expression of CAS9 in hESCs reduced the efficiency to repair DNA DSB damage via NHEJ pathway (Fig. 5A), but did not affect the efficiency to repair DNA DSB damage via HDR pathway (Fig. 5B). In addition, the expression of CAS9 in hESCs significantly increased the rate of spontaneous mutation of the HPRT gene in hESCs, indicating that CAS9 induces genomic instability (Fig. 5C). Therefore, the expression of CAS9 induces genomic instability in hESCs. 
Table 1. Primers used in this study.

Sequence $\left(5^{\prime}-3^{\prime}\right)$

\begin{tabular}{|c|c|}
\hline \multicolumn{2}{|l|}{ Primers for cloning } \\
\hline $\begin{array}{l}\text { Fuw-teto-CAS9/XCAS9/dCAS9-pgk- } \\
\text { puro Gibson F }\end{array}$ & TATCGATAAGCTTGATATCGAATTCTCAGGCACCGGGCTTGCGGG \\
\hline $\begin{array}{l}\text { Fuw-teto-CAS9/XCAS9/dCAS9-pgk- } \\
\text { puro Gibson R }\end{array}$ & ATCCAGCCTCCGCGGCCCCGAATTCGCCACCATGGACAAGAAGTACAGCAT \\
\hline Fuw-teto-control-pgk-puro F & AATTCGCCACCATGGATTACAAAGACGATGACGATAAGTAGA \\
\hline Fuw-teto-control-pgk-puro R & CCGGTCTACTTATCGTCATCGTCTTTGTAATCCATGGTGGCG \\
\hline plenti-CAS9-pgk-puro Gibson F & ACCGACTCTAGAGGATCCGCCACCATGGACAAGAAGTACAGCATCGGCC \\
\hline plenti-CAS9-pgk-puro Gibson R & TCCAGAGGTTGATTGTCGACCTACTTATCGTCATCGTCTT \\
\hline Fuw-teto-95-pgk-puro Gibson F & GACCGATCCAGCCTCCGCGGCCCCGAATTCGCCACCATGGACAGCTTCTTCCACAGACTG \\
\hline Fuw-teto-95-pgk-puro Gibson R & TGGAAAAGGCGCAACCCCAAACCGGTCTACTTATCGTCATCGTCTTTGTAATC \\
\hline plenti-719-pgk-puro Gibson F & GACCGATCCAGCCTCCGCGGCCCCGAATTCGCCACCATGAGCCTGCACGAGCACATT \\
\hline Fuw-teto-719-pgk-puro Gibson R & TGGAAAAGGCGCAACCCCAAACCGGTCTACTTATCGTCATCGTCTTTGTAATC \\
\hline Fuw-teto-910-pgk-puro Gibson F & GACCGATCCAGCCTCCGCGGCCCCGAATTCGCCACCATGGAACTGGATAAGGCCGGCTT \\
\hline Fuw-teto-910-pgk-puro Gibson R & TGGAAAAGGCGCAACCCCAAACCGGTCTACTTATCGTCATCGTCTTTGTAATC \\
\hline Fuw-teto-1100-pgk-puro Gibson F & GACCGATCCAGCCTCCGCGGCCCCGAATTCGCCACCATGGTGCAGACAGGCGGCTTCA \\
\hline Fuw-teto-1100-pgk-puro Gibson R & TGGAAAAGGCGCAACCCCAAACCGGTCTACTTATCGTCATCGTCTTTGTAATC \\
\hline plenti-control-pgk-puro $\mathrm{F}$ & GATCCGCCACCATGTACCCATACGACGTCCCAGACTACGCTTAGG \\
\hline plenti-control-pgk-puro $\mathrm{R}$ & TCGACCTAAGCGTAGTCTGGGACGTCGTATGGGTACATGGTGGCG \\
\hline plenti-Ku86-pgk-puro Gibson F & $\begin{array}{l}\text { GACACCGACTCTAGAGGATCCGCCACCATGTACCCATA } \\
\text { CGACGTCCCAGACTACGCTATGGTGCGGTCGGGGAATAAG }\end{array}$ \\
\hline plenti-Ku86-pgk-puro Gibson R & $\begin{array}{l}\text { TCACAAATTTTGTAATCCAGAGGTTGATTGTCGACGAATTC } \\
\text { CTATATCATGTCCAATAAATCGTCC }\end{array}$ \\
\hline Fuw-teto-Cpf1-pgk-puro Gibson F & AAGCCCTCGAACTGTGTCATGGTGGCGAATTCGGGGCCGCGGAGGCTGGAT \\
\hline Fuw-teto-Cpf1-pgk-puro Gibson R & AGACGATGACGATAAGTAGACCGGTTTGGGGTTGCGCCTTTTCCA \\
\hline \multicolumn{2}{|l|}{ Primers for RT-qPCR } \\
\hline Puma F & ACGACCTCAACGCACAGTACGA \\
\hline Puma R & CCTAATTGGGCTCCATCTCGGG \\
\hline $\mathrm{P} 21 \mathrm{~F}$ & ACCTGGAGACTCTCAGGGTCG \\
\hline P21 R & TTAGGGCTTCCTCTTGGAGAAGAT \\
\hline Perp F & TCATCCTGTGCATCTGCTTC \\
\hline Perp R & GGGTTATCGTGAAGCCTGAA \\
\hline Noxa F & ACCAAGCCGGATTTGCGATT \\
\hline Noxa $\mathrm{R}$ & ACTTGCACTTGTTCCTCGTGG \\
\hline$\beta$-actin F & AGCGAGCATCCCCCAAAGTT \\
\hline$\beta$-actin R & GGGCACGAAGGCTCATCATT \\
\hline
\end{tabular}

High fidelity or nuclease-dead CAS9 variants and Cpf1 induce DNA DSB damage

In an attempt to improve the fidelity of CAS9 in gene editing, recent studies have described CAS9 variants such as xCAS9 that appear to have higher fidelity (Hu et al., 2018). However, similarly to CAS9, XCAS9 also interacted with
KU86 and induced DNA DSB damage independently of the exogenous gRNA (Fig. 5D and 5E). In addition, XCAS9 impaired DNA DSB repair via NHEJ but did not affect the DNA DSB repair via HDR (Fig. 5A). Therefore, XCAS9 is also a genome mutator that can promote DNA DSB damage in the absence of any gRNAs. 
Mammalian cells might express endogenous gRNA-like small RNA that could work with CAS9 to induce DNA damage. To test this possibility, we examined the impact of the expression of dCAS9, which is defective in the nuclease activity (Gilbert et al., 2013; Maeder et al., 2013), on DNA DSB damage. Similar to CAS9 and XCAS9, dCAS9 also interacted with KU86 (Fig. 6A). In addition, the expression of dCAS9 in hESCs also promoted DNA DSB damage and genetic mutations at HPRT locus (Fig. 6B and 6C). While the impact of dCAS9 on DNA damage appeared to be less dramatic than CAS9, the results demonstrate that CAS9 can induce DNA damage independent of its nuclease activity. Similarly to CAS9, Cpf1 also interacted with KU86 and activated DNA DSB damage (Fig. 6D and 6E).

Previous studies evaluated the genomic stability of cells after the site-specific gene editing induced by CAS9 + gRNA, suggesting that the specificity of gRNA and the delivery method of CAS9/gRNA could be optimized to improve the fidelity and safety of this gene editing technology (Haapaniemi et al., 2018; Ihry et al., 2018; Kosicki et al., 2018). Our data demonstrate that CAS9 and its high-fidelity variant XCAS9 are genome mutators by promoting DNA DSB damage and genetic mutations independently of gRNA. This intrinsic oncogenic activity of CAS9 is achieved by disrupting DNA-PK complex, leading to impaired DNA DSB repair via NHEJ pathway. In addition, it has been well documented that defects in the DNA-PK function will promote DNA DSB damage and genetic instability (Davis et al., 2014). Therefore, our findings raise concerns for the safety of CRISPR/ CAS9 system based human therapy. The development of CAS9 variants that retain the gene editing activity of wild type CAS9 but do not disrupt DNA-PK activity might help to improve the fidelity of gene editing technology and safety of the CRISPR/CAS9 system.

\section{MATERIALS AND METHODS}

Cell lines, lentivirus production and transduction

Human embryonic stem cell line $\mathrm{H} 9$ was obtained from WiCell Research Institute, Inc. and cultured with mTeSR1 medium (STEMCELL, USA). Human fibroblasts were used between passages 3 to 12. The HEK 293 FT and HEK 293T cell lines were purchased from Thermo Scientific. Human fibroblasts and HEK 293 FT were cultured in DMEM (Gibco) supplemented with 10\% fetal bovine serum (FBS) (Hyclone) and $1 \%$ penicillin-streptomycin (Pen/Strep) (Gibco) at $37{ }^{\circ} \mathrm{C}$ with $5 \% \mathrm{CO}_{2}$. The lentivirus production and transduction were performed as we previously described (Kim et al., 2019). All cell lines were routinely checked for mycoplasma by a PCR detection kit.

\section{Expression vector construction}

To construct vectors that express genes inducibly, CAS9, XCAS9, dCAS9 or Cpf1 cDNA was cloned into TetO-
Fuw-PGK-Puro vector modified from TetO-Fuw-OSKM vector (Addgene plasmid 20321) linearized by EcoRI/Agel digestion using Gibson Assembly (2× NEBuilder HiFi DNA Assembly Master Mix) as previously described (Kim et al., 2019). To generate KU86 and CAS9 deletional mutants, pLenti-CMV-GFP vector (Addgene 17448) was linearized by BamHI/Sall digestion and ligated with the PCR products of KU86 and different domains of CAS9 by Gibson assembly. The PCR primers were provided in Table 1.

\section{Western blot analysis and Co-immunoprecipitation (Co- IP)}

Cells were extracted for total proteins using lysis buffer containing Protease and Phosphatase Inhibitor Cocktail (Cell Signaling Technology CST). For nuclear protein extraction, nuclear and cytoplasm protein extraction kit (Thermo Fisher Scientific) was used following the instruction. Protein was separated on $6 \%-15 \%$ SDS PAGE and transferred to $0.45 \mu \mathrm{m}$ nitrocellulose membranes (Merck Millipore USA), which were blocked with the blocking buffer ( $5 \%$ skim milk in TBS with $0.05 \%$ Tween 20 ) and incubated with primary antibodies at $4{ }^{\circ} \mathrm{C}$ overnight. The membranes were

Table 2. Antibodies used in this study

\begin{tabular}{ll}
\hline Antibody & Source and catalog \\
Anti-yH2AX & Cell signaling (9718S, 80312S) \\
Anti-H2AX & Cell signaling (7631S) \\
Anti-p53 & Santa Cruze (sc-126) \\
Anti-pp53 & Cell signaling (9286S) \\
Anti-CHK1 & Cell signaling (2360S) \\
Anti-pCHK1 & Cell signaling (12302S) \\
Anti-H3 & Abcam (ab1971) \\
Anti-KU86 & Santa Cruze (sc-5280), Abcam \\
& (ab119935), Cell signaling \\
Anti-KU70 & (2753s) \\
Anti-DNA PKcs & Abcam (ab92450) \\
Anti-BRCA1 & Abcam (ab70250) \\
Anti-p-BRCA1 & Cell signaling (14823S) \\
Anti-CHK2 & Cell signaling (9009S) \\
Anti-pCHK2 & Cell signaling (6334S) \\
Anti-CAS9 & Cell signaling (2197S) \\
Anti- $3-a c t i n$ & Cell signaling (14697S), Abcam \\
Anti-Flag & (ab189380), Novus Biologicals \\
Anti-a-tubulin & (NBP2-52717) \\
\hline & Cell signaling (4970S) \\
& Santa Cruze (sc-73242) \\
\hline &
\end{tabular}


A

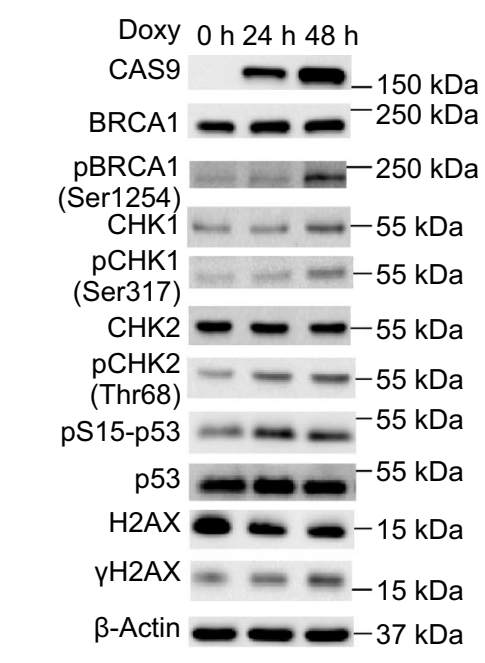

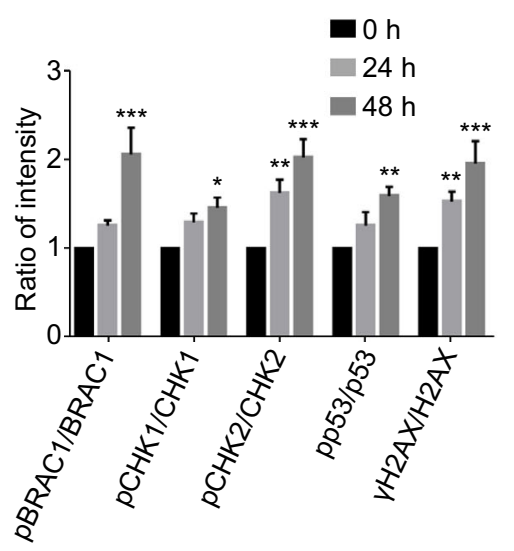

B

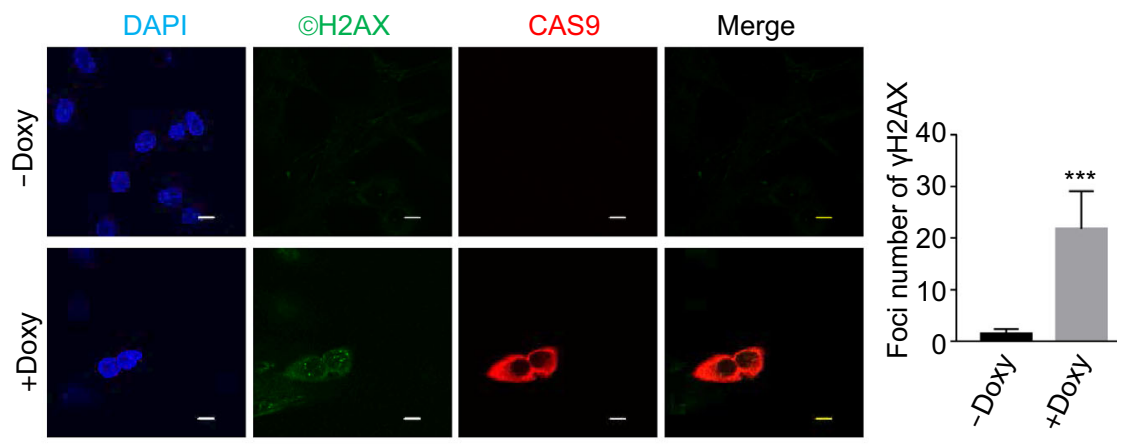

C
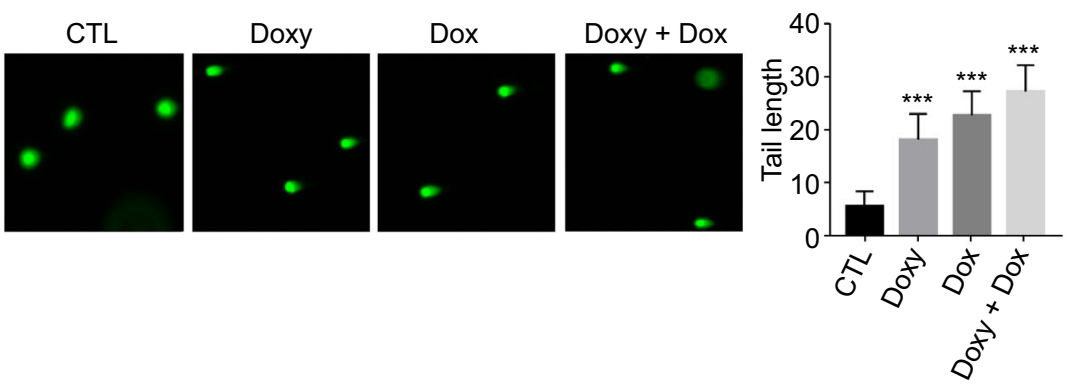

Figure 3. The expression of CAS9 in human fibroblasts promotes DNA DSB damage and activates DNA damage response pathways. (A) The expression of CAS9 in human fibroblasts activates DNA damage responses. The expression of CAS9 was induced with $2 \mu \mathrm{g} / \mathrm{mL}$ Doxy treatment. The relative levels of phosphorylation of BRCA1, CHK1, CHK2 and p53 are indicated at the bottom. $n=3$. Data are presented as mean value \pm SD. ${ }^{*} P<0.05$, ${ }^{* *} P<0.01$, ${ }^{* * *} P<0.001$. (B) The expression of CAS9 increased the number of $\mathrm{YH} 2 \mathrm{AX}$ foci in human fibroblasts. CTL or CAS9, human fibroblasts with CAS9 inducible expression cassette plated on chamber slides were treated with or without $2 \mu \mathrm{g} / \mathrm{mL}$ doxycycline for 3 days. The expression of CAS9 and $\mathrm{yH} 2 \mathrm{AX}$ foci was revealed by immunoflourescence analysis. Representative images are shown. Scale bar, $10 \mu \mathrm{m}$. Unpaired $t$ test. $n=20$. Data are presented as mean values $\pm \mathrm{SD}$. ${ }^{* \star *} P<0.001$. (C) CAS9 induces DNA DSB damage in human fibroblasts. CTL, human fibroblasts with lentiviral empty vector were treated with $2 \mu \mathrm{g} / \mathrm{mL}$ doxycycline for three days; Doxy, Dox, Doxy + Dox, human fibroblasts with lentiviral CAS9 inducible expression vector were treated with $2 \mu \mathrm{g} / \mathrm{mL}$ doxycycline for 3 days or $0.5 \mu \mathrm{mol} / \mathrm{L}$ Dox for $2 \mathrm{~h}$ or $2 \mu \mathrm{g} / \mathrm{mL}$ doxycycline for three days $+0.5 \mu \mathrm{mol} / \mathrm{L}$ Dox for $2 \mathrm{~h}$, respectively. Representative images are shown. $n=40$. Unpaired t test. Data are presented as mean value $\pm \mathrm{SD}$. ${ }^{* \star} P<0.01$. 
incubated with secondary antibodies at room temperature for $1 \mathrm{~h}$ and detected with Supersignal West Pico or Dura exposure buffer (Thermo Fisher Scientific). For Co-IP, the cells were collected and lysed with IP lysis buffer (Thermo Fisher Scientific) containing protease inhibitor cocktail (Thermo Fisher Scientific) on ice for $30 \mathrm{~min}$. After the centrifugation at $12,000 \times g$ for $20 \mathrm{~min}$ at $4{ }^{\circ} \mathrm{C}$, the supernatants were immunoprecipitated with antibodies followed by incubating with magnetic protein A/G beads (Pierce) for $4 \mathrm{~h}$. For IP analysis of phosphorylated proteins, cells were collected in the IP lysis buffer containing Protease and Phosphatase Inhibitor Cocktail. The antibodies used were provided in Table 2.

\section{Proximity ligation analysis}

hESCs with inducible CAS9 expression vector were plated on chamber slides and treated with $2 \mu \mathrm{g} / \mathrm{mL}$ doxycycline for 2 days. After the treatment, the cells were washed with PBS twice and then fixed with 4\% paraformaldehyde (PFA) for 15 min at room temperature. After washing with PBS three times, cells were permeabilized with $0.3 \%$ Triton $X-100$ in PBS for $10 \mathrm{~min}$ at room temperature. Then Duolink ${ }^{\circledR}$ In Situ Red Starter Kit Mouse/Rabbit (Sigma, DUO92101) was used to reveal the interaction between CAS9 and KU86 as instructed by the manufacturer. The antibodies of different species (rabbit anti-CAS9 antibody, mouse anti-KU86 antibody) were used to detect the proteins. DAPI (blue) was used to stain the nucleus.

\section{Immunofluorescence staining}

$1 \times 10^{3} \mathrm{H} 9$ or fibroblast cells were seeded onto the chamber slides coated with matrigel (Corning) and treated with $2 \mu \mathrm{g} /$ $\mathrm{mL}$ doxycycline for 2 days. After the treatment, cells were washed with PBS twice, and then fixed with $4 \%$ paraformaldehyde (PFA) for $15 \mathrm{~min}$ at room temperature. After washing with PBS three times, cells were permeabilized with $0.3 \%$ Triton $\mathrm{X}-100$ in PBS for $10 \mathrm{~min}$, blocked with $2 \%$ bovine serum albumin (BSA) in PBS for $1 \mathrm{~h}$ at room temperature, stained with anti-CAS9 antibody (Abcam, $1: 100)$ and anti-yH2AX antibody (CST, 1:100) at $4{ }^{\circ} \mathrm{C}$ overnight, followed by simultaneous incubation with Alexa Fluor 568-conjugated anti-mouse secondary antibody and Alexa Fluor 488-conjugated anti-rabbit antibody for $1 \mathrm{hr}$ at room temperature. Slides were mounted using VECTASHIED solution (Vector) with DAPI. The images were acquired as previously described (Chen et al., 2018).

\section{Comet assay analysis}

Comet assay was carried out as we previously described (Xiong et al., 2015). Briefly, hESCs or fibroblasts plated on the matrigel-coated 6 -well plates were treated with $2 \mu \mathrm{g} / \mathrm{mL}$ doxycycline for 2 days, followed with or without the treatment with $0.5 \mu \mathrm{mol} / \mathrm{L}$ doxorubicin for $4 \mathrm{~h}$. Cells were harvested,
Figure 4. CAS9 interacts with KU86 and disrupts the formation of DNA-PK. (A and B) Reciprocal immunoprecipitation shows the interaction between CAS9 and KU86. Protein extracts from hESCs expressing CAS9 were immunoprecipitated with anti-KU86 (A) or anti-CAS9 (B), and immune precipitates were analyzed for the presence of KU86 and CAS9. (C) The interaction between CAS9 and KU86 was confirmed by the proximity ligation analysis (PLA). Cell nucleus were revealed by DAPI (Blue) staining and the CAS9-KU86 interaction indicated by red color. Scale bar, $25 \mu \mathrm{m}$. Unpaired $t$ test. $n=20$. Data are presented as mean value \pm SD. ${ }^{\star * \star} P<0.001$. (D) Mapping the domain of CAS9 involved in the interaction with KU86. The Flag-tagged deletional mutants of CAS9 expressed in 293FT cells were immunoprecipitated with anti-flag antibody. Immune precipitates were analyzed for the presence of CAS9 mutants and KU86. (E) The expression of the PAM domain (1100) of CAS9 disrupted the interaction between CAS9 and KU86. The levels of CAS9, KU86, PAM in the input and immunoprecipitate were analyzed by Western blot. The ratio of CAS9 versus KU86 in the immunoprecipitate is shown at the bottom. (F) CAS9 disrupts the formation of DNA-PK complex. Protein extracts of cells in the presence and absence of CAS9 and DOX treatment were immunoprecipitated with antiKU86 antibody. The levels of KU70, DNA-PKcs and CAS9 in the immunoprecipitate were analyzed. The relative ratios of DNA-PKcs versus KU86 or KU70 versus KU86 are indicated.

washed with ice-cold PBS twice, resuspended at a density of $10^{5}$ cells $/ \mathrm{mL}$, mixed with agarose at a 1:10 ratio, spread onto 3-well Comet Assay slides, and kept in dark for $15 \mathrm{~min}$ at room temperature. Slides were immersed in chilled lysis solution for $15 \mathrm{~min}$, washed with chilled TBE buffer three times and electrophoresed in chilled TBE (Tris-borate-EDTA) buffer for $15 \mathrm{~min}$ at $20 \mathrm{~V}$. Slides were then fixed in $70 \%$ ethanol and dried, and DNA was labeled with Vista Green DNA Dye diluted with TBE buffer. Images were captured and analyzed using Image $\mathrm{J}$ software.

\section{RNA purification and quantitative PCR analysis}

The RNA extraction and qPCR were performed as we previously described (Kim et al., 2019). The primers used for qPCR were listed in Table 1.

\section{Cell viability}

hESC cells were digested with TripLe (Gibco) to prepare single cells. $4 \times 10^{3}$ cells/well were plated onto each well of the 96-well plates with triplicate wells per sample. Cell Counting Kit (CCK8, DoJindo) was used to evaluate cell viability according to the manufacturer's instructions. 


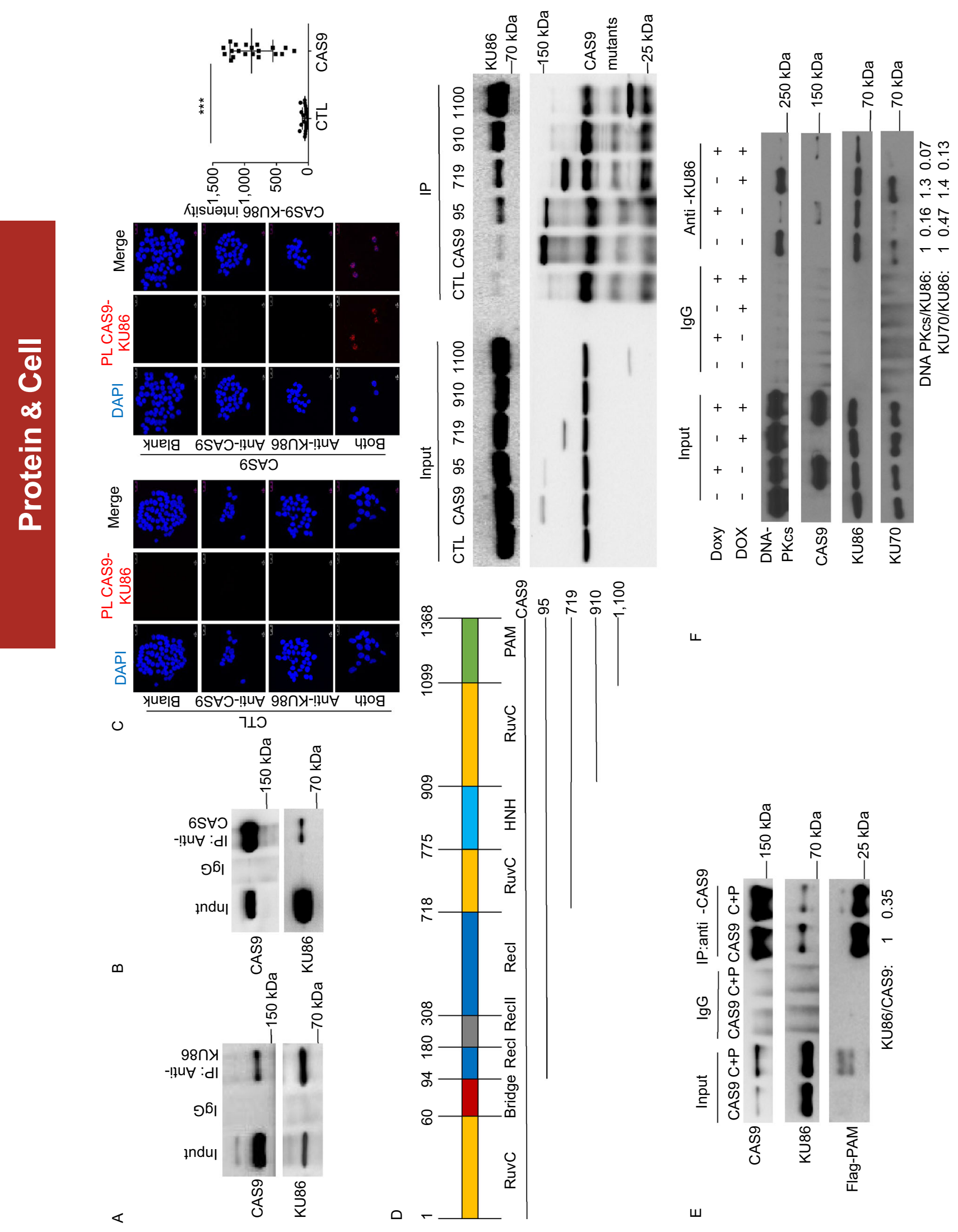




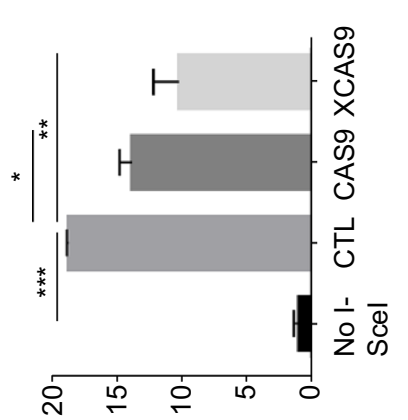

Кэนә!э!щ Г
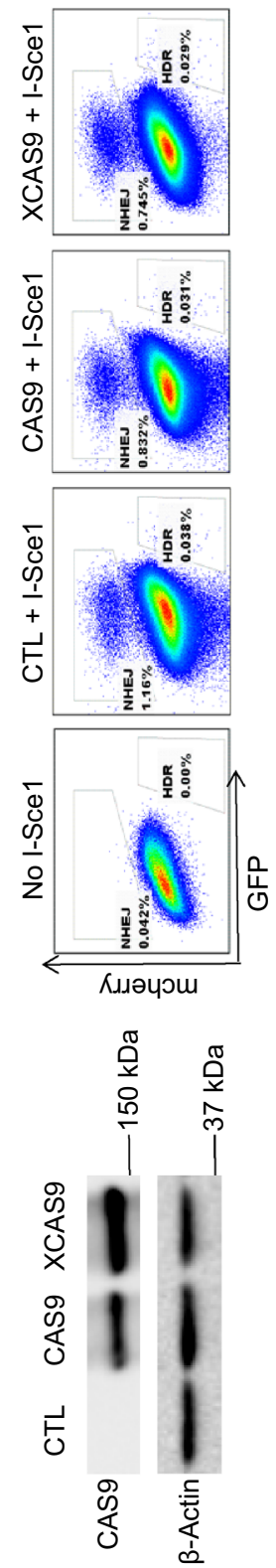

$\varangle$

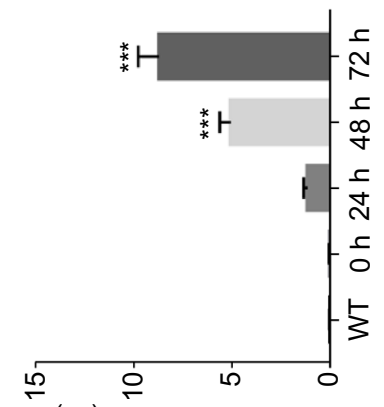

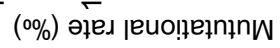
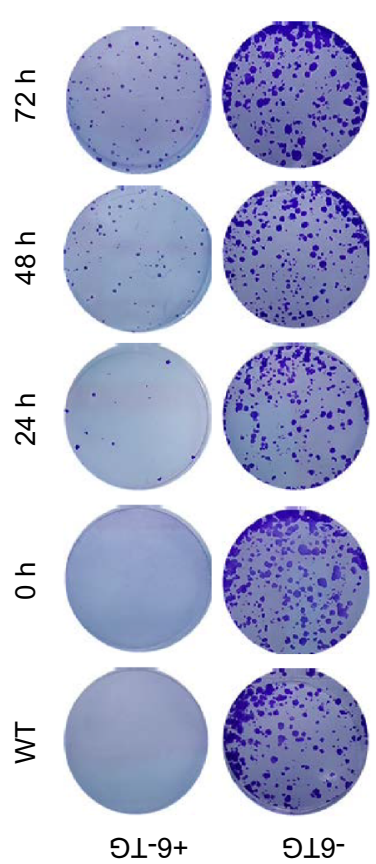

$\circlearrowleft$

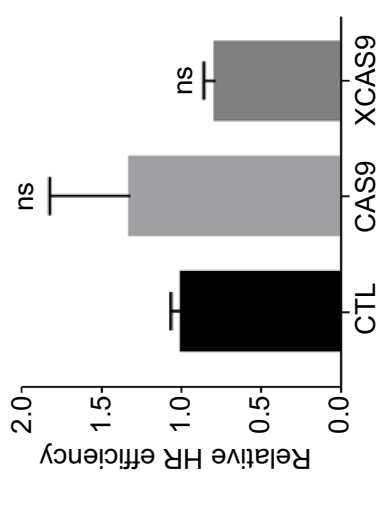

$\infty$

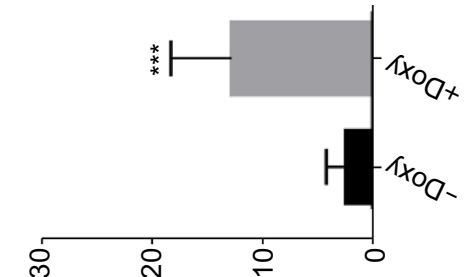

!อง $\mathrm{X} \forall \mathrm{ZH} \wedge$ jo dəquinN
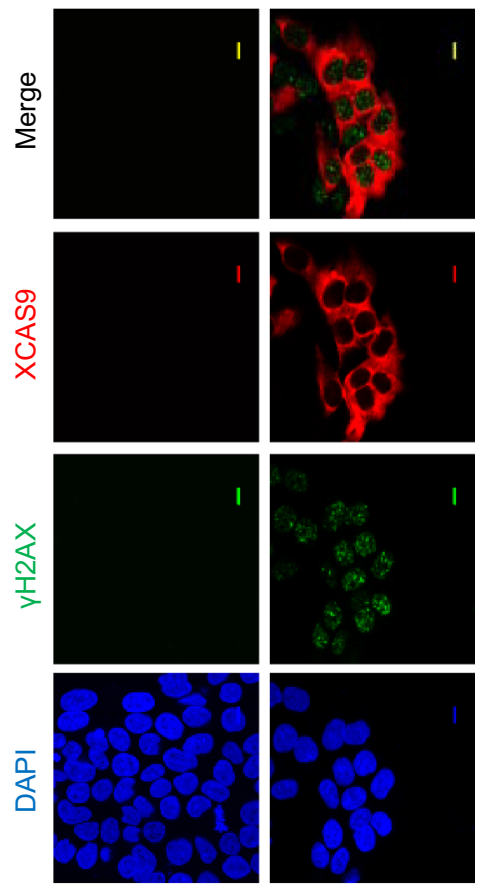

Kxoa-

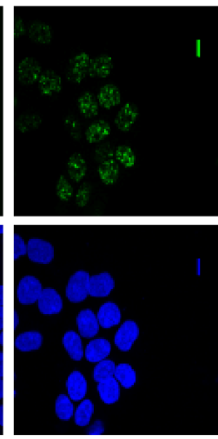

KxoO+

ш

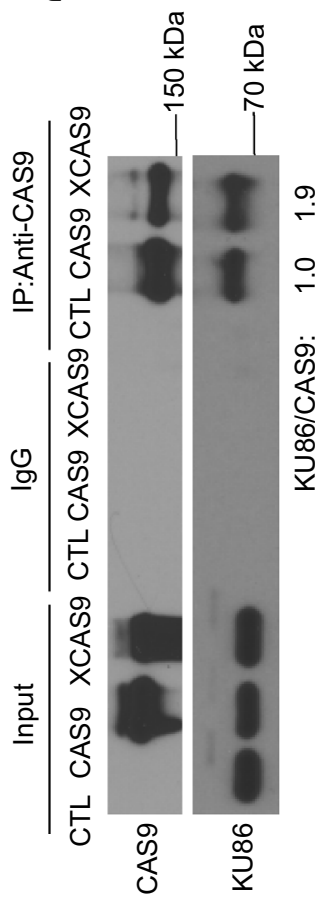


Figure 5. Both CAS9 and XCAS9 impair NHEJ and induce genetic mutations. (A and B) Expression of CAS9 and XCAS9 impairs NHEJ. Traffic Light Reporter system was established in 293 cells harboring the CAS9 and XCAS9 inducible expression vectors. After the induction of CAS9 and XCAS9 expression with $2 \mu \mathrm{g} / \mathrm{mL}$ doxycycline for 3 days (left panel), the efficiency of NHEJ (mcherry) and HDR (GFP) was analyzed by flow cytometry (middle panel). Statistic analysis of the efficiency of NHEJ (left panel of A) and HDR (B) is presented. $n=3$. Data are presented as mean values $\pm \mathrm{SD}$. ${ }^{*} P<0.05$, ${ }^{*} P<0.01$, ${ }^{* * *} P<0.001$. ns, non-significant. (C) The expression of CAS9 in hESCs induces genomic mutations at the endogenous HPRT locus. After hESCs harboring CAS9 inducible expression vector were selected with HAT medium for 5 days, they were treated with $2 \mu \mathrm{g} / \mathrm{mL}$ doxycycline for CAS9 expression for various time periods, and subsequently, treated with $5 \mu \mathrm{g} / \mathrm{mL} 6-\mathrm{TG}$ or mock treated for 4 days. Mutational rate is calculated as the ratio of colony number in 6-TG treated samples versus untreated controls. $n=3$. Data are presented as mean values \pm SD. ${ }^{* \star} P<$ 0.001. (D) XCAS9 interacts with KU86. Protein extracts from 293FT cells expressing Flag-tagged CAS9 or XCAS9 were immunoprecipitated with anti-Flag antibody. The immune precipitates were analyzed for the presence of CAS9, XCAS9 and KU86. The relative ratio of KU86 versus CAS9 or XCAS9 is indicated. (E) The expression of XCAS9 increases the number of $\mathrm{YH} 2 \mathrm{AX}$ foci in hESCs. hESCs harboring XCAS9 inducible expression vector were treated with or without $2 \mu \mathrm{g} / \mathrm{mL}$ doxycycline for 3 days. $n=20$. Scale bar, $10 \mu \mathrm{m}$. Data are presented as mean values \pm SD. ${ }^{* *} P<0.01$.

\section{Detection of spontaneous mutations of the HPRT gene in hESCs}

The detection of spontaneous mutations of the HPRT gene in hESCs was performed as previously described (Kang et al., 2002). Briefly, hESCs with empty vector or with CAS9 inducible expression vector were treated with $1 \times$ hypoxanthine-aminopterin-thymidine (HAT) medium for 5 days to eliminate hESCs with HPRT mutations. After replating, $2 \mu \mathrm{g} /$
$\mathrm{mL}$ doxycycline was added to induce the expression of CAS9 for $24 \mathrm{~h}, 48 \mathrm{~h}$ or $72 \mathrm{~h}$. Cells were harvested and plated on triplicate 6 wells at a density of $10^{5}$ cells/well. These cultures were mock treated or treated with $5 \mu \mathrm{g} / \mathrm{mL}$ 6-thioguanine (6-TG) for 3 days to select for hESCs lacking functional HPRT. Cultures were incubated for 8-10 days and colonies fixed with $4 \%$ paraformaldehyde (PFA) for $10 \mathrm{~min}$ at RT. After washing with PBS three times, colonies were visualized by staining with crystal violet. The number of colonies was counted using the Image $\mathrm{J}$ software.

\section{Detection of DNA DSB repair via NEHJ and HDR pathways}

We used the Traffic Light Reporter system to evaluate the efficiency to repair DNA DSBs via NHEJ and HDR pathways as previously described (Gomez-Cabello et al., 2013). Briefly, HEK293FT cells were transduced with Traffic Light Reporter virus and $5 \mu \mathrm{g} / \mathrm{mL}$ polybrene. After $48 \mathrm{~h}$, cells were selected with $1 \mu \mathrm{g} / \mathrm{mL}$ puromycin for 3 days. Surviving clone was picked, expanded and verified with PCR to confirm the integration of the reporter harboring an I-sce1 site. Reporter cells were transduced with the control or inducible CAS9 expression lentivirus. $6 \times 10^{4}$ control or cells with inducible CAS9 expression vector were plated onto the triplicate wells of 48-well plates. After the induction of the expression of CAS9, the cells were transduced with I-Scel-T2A-IFP or control empty lentivirus. Ten days later, cells were collected and analyzed by flow cytometry. The results were analyzed by Flowjo software.

\section{Statistical analysis}

Any statistical method was used to calculate group variation was not estimated before experiments. Statistical significance was assayed with GraphPad Prism. For comparing two groups, $t$-test was used. ${ }^{*} P<0.05,{ }^{* *} P<0.01,{ }^{* * *} P<$ 0.001 , ns means non-significant. 

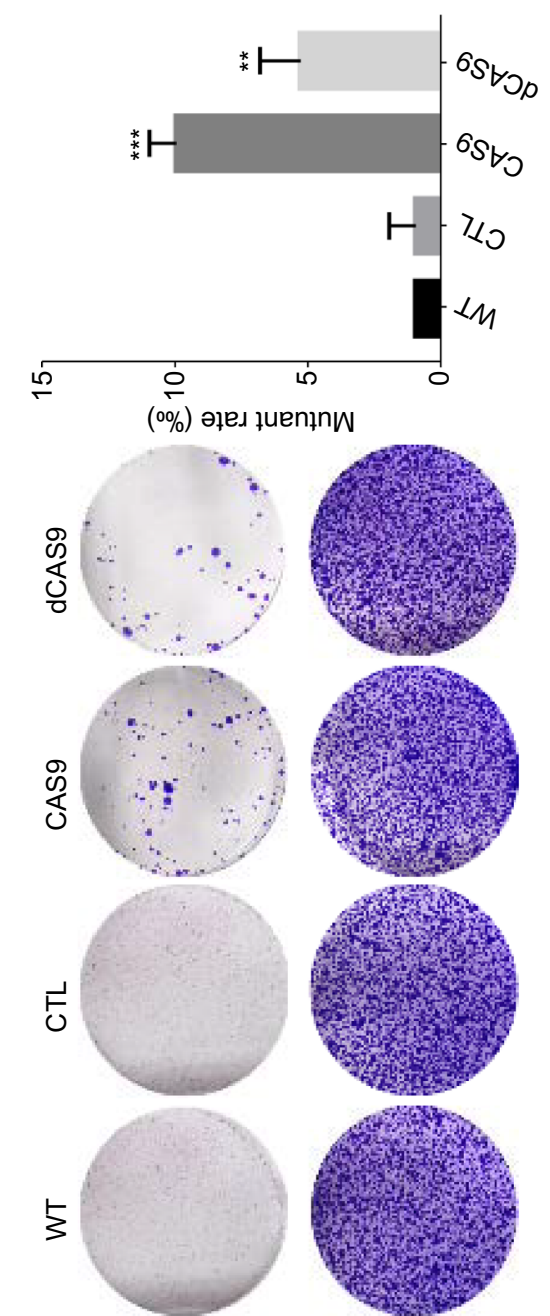

งเ-9+
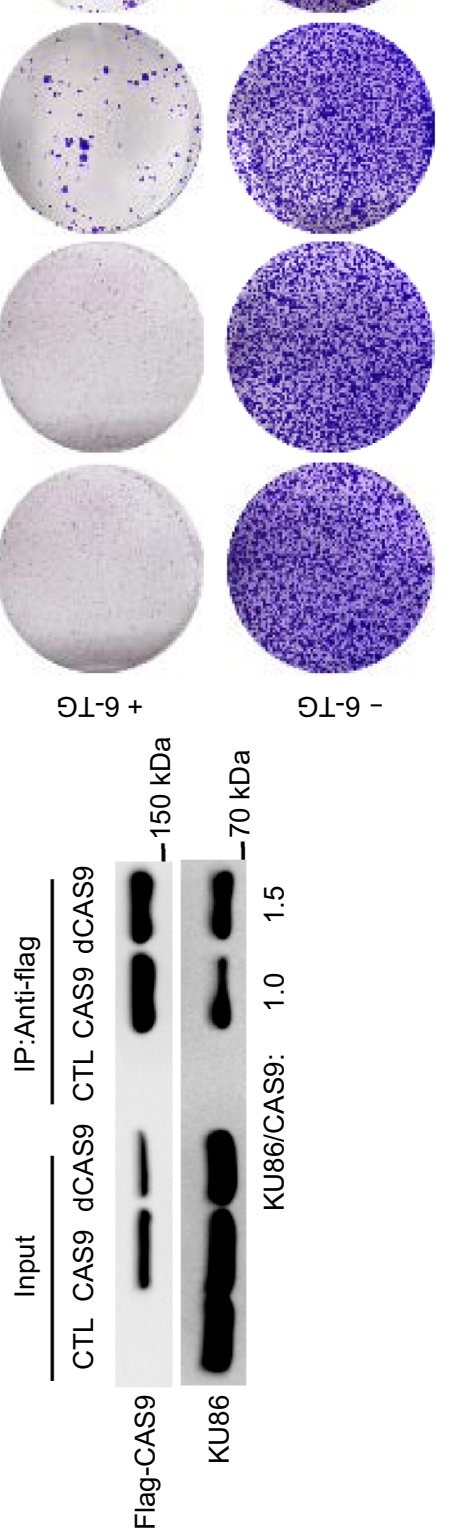

๑ะ-9 -

u

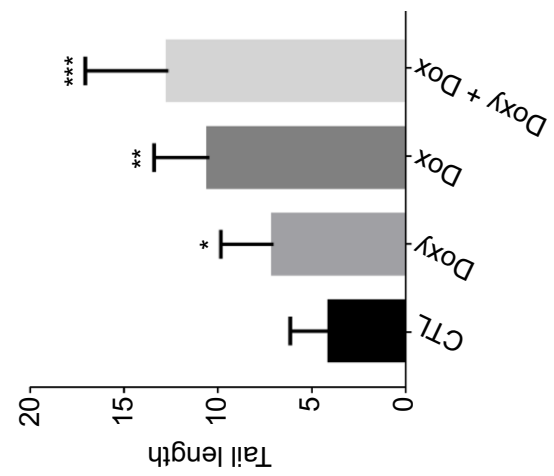

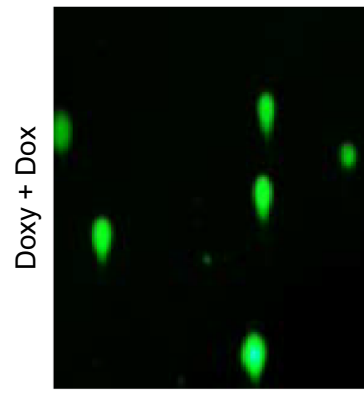
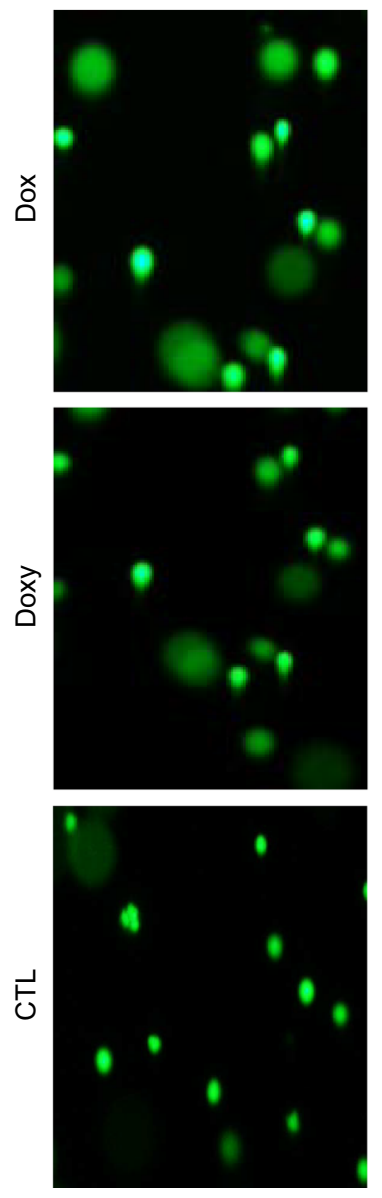

ш

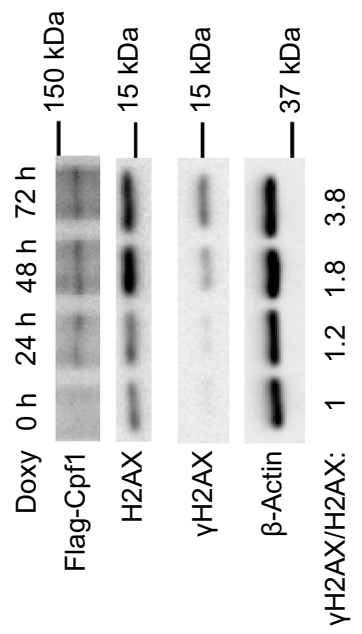

$\infty$
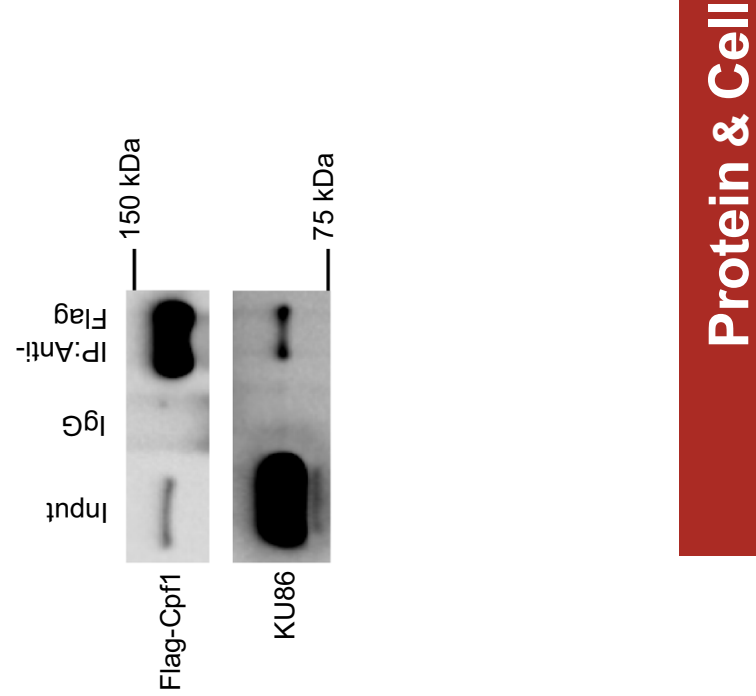
$4 \quad$ Figure 6. dCAS9 and Cpf1 impair NHEJ and induce genetic mutations. (A) Co-immunoprecipitation assay confirmed the interaction between dCAS9 and KU86. (B) Comet assay analysis of DNA damage in hESCs expressing dCAS9 or treated with doxorubicin. CTL, human fibroblasts with lentiviral empty vector were treated with $2 \mu \mathrm{g} / \mathrm{mL}$ doxycycline for three days; Doxy, Dox, Doxy + Dox, human fibroblasts with lentiviral CAS9 inducible expression vector were treated with $2 \mu \mathrm{g} / \mathrm{mL}$ doxycycline for 3 days or $0.5 \mu \mathrm{mol} / \mathrm{L}$ Dox for $2 \mathrm{~h}$ or $2 \mu \mathrm{g} / \mathrm{mL}$ doxycycline for three days $+0.5 \mu \mathrm{mol} / \mathrm{L}$ Dox for $2 \mathrm{~h}$, respectively. Tail length was analyzed using Image $\mathrm{J}$ software. Data are represented as mean $\pm \mathrm{SD}$. ${ }^{\star} P<0.05$, ${ }^{\star \star} P<0.01$, ${ }^{\star \star *} P<$ 0.001 . (C) The expression of dCAS9 induces mutation of endogenous HPRT gene. WT, WT hESCs; CTL, CAS9, dCAS9, hESCs with empty expression vector, CAS9 inducible expression vector. Cells with dCAS9 inducible expression vector were treated with $2 \mu \mathrm{g} / \mathrm{mL}$ doxycycline for 3 days before HAT treatment. $n=3$. Data are presented as mean value \pm SD. ${ }^{* *} P<$ $0.01,{ }^{* * *} P<0.001$. (D) The expression of Cpf1 increased the levels of $\mathrm{YH} 2 \mathrm{AX}$. (E) Cpf1 interacts with KU86 as confirmed by Co-immunoprecipitation. Protein extract of Flag-tagged Cpf1 was immunoprecipitated with anti-Flag antibody and the presence of Cpf1 and KU86 in the immunoprecipitate was examined by Western blot.

\section{AUTHOR CONTRIBUTIONS}

SX, JK, XF and YX designed the experiments and analyzed the data. SX, JK, QT performed the majority of the experiments with the help from $Q C, J L$. XF and $Y X$ provided the administrative support. $S X, Y X$ and $X F$ were responsible for the initial draft of the manuscript, whereas other authors contributed to the final edited versions.

\section{ACKNOWLEDGMENTS}

We thank Dr. Qingjiao Li for help with data analysis. This study was supported by the a grant from the National High-tech R\&D Program (863 Program No. 2015AA020310), National Natural Science Foundation of China (Nos. 815300045, 91959204, 81930084, 81871197, U1601222), the leading talents of Guangdong Province Program (No. 00201516), a grant from the Key Research and Development Program of Guangdong Province (2019B020235003), Major basic research developmental project of the Natural Science Foundation of Guangdong Province (2014A030308018), Development and Reform Commission of Shenzhen Municipality (S2016004730009), and Shenzhen "Sanming" Project of Medicine (SZSM201602102).

\section{ABBREVIATION}

CRISPR, clustered regularly interspaced short palindromic repeats; CAS9, CRISPR associated protein 9; Cpf1, CRISPR-associated endonuclease in Prevotella and Francisella 1; DNA-PK, DNAdependent protein kinase; DSB, double-stranded break; NHEJ, non-homologous end joining; DNA-PKcs, DNA dependent protein kinase catalytic subunit; hiPSC, human induced pluripotent stem cells; hESC, human embryonic stem cells; HPRT1, hypoxanthine phosphoribosyltransferase 1

\section{COMPLIANCE WITH ETHICS GUIDELINES}

Shuxiang Xu, Jinchul Kim, Qingshuang Tang, Qu Chen, Jingfeng Liu, Yang $\mathrm{Xu}$ and Xuemei Fu declare that they have no conflict of interest. All institutional and national guidelines for the care and use of laboratory animals were followed.

\section{OPEN ACCESS}

This article is licensed under a Creative Commons Attribution 4.0 International License, which permits use, sharing, adaptation, distribution and reproduction in any medium or format, as long as you give appropriate credit to the original author(s) and the source, provide a link to the Creative Commons licence, and indicate if changes were made. The images or other third party material in this article are included in the article's Creative Commons licence, unless indicated otherwise in a credit line to the material. If material is not included in the article's Creative Commons licence and your intended use is not permitted by statutory regulation or exceeds the permitted use, you will need to obtain permission directly from the copyright holder. To view a copy of this licence, visit http:// creativecommons.org/licenses/by/4.0/.

\section{REFERENCES}

Barrangou R, Doudna JA (2016) Applications of CRISPR technologies in research and beyond. Nat Biotechnol 34:933-941

Chen J, Li WJ, Cui K, Ji KY, Xu SX, Xu Y (2018) Artemisitene suppresses tumorigenesis by inducing DNA damage through deregulating c-Myc-topoisomerase pathway. Oncogene 37:5079-5087

Cong L, Ran FA, Cox D, Lin S, Barretto R, Habib N, Hsu PD, Wu X, Jiang W, Marraffini LA et al (2013) Multiplex genome engineering using CRISPR/Cas systems. Science 339:819-823

Davis AJ, Chen BPC, Chen DJ (2014) DNA-PK: a dynamic enzyme in a versatile DSB repair pathway. DNA Repair 17:21-29

Dever DP, Bak RO, Reinisch A, Camarena J, Washington G, Nicolas CE, Pavel-Dinu M, Saxena N, Wilkens AB, Mantri S et al (2016) CRISPR/Cas9 beta-globin gene targeting in human haematopoietic stem cells. Nature 539:384-389

Gilbert Luke A, Larson Matthew H, Morsut L, Liu Z, Brar Gloria A, Torres Sandra E, Stern-Ginossar N, Brandman O, Whitehead Evan H, Doudna Jennifer A et al (2013) CRISPR-mediated modular RNAguided regulation of transcription in eukaryotes. Cell 154:442-451

Gomez-Cabello D, Jimeno S, Fernández-Ávila MJ, Huertas P (2013) New tools to study DNA double-strand break repair pathway choice. PLoS ONE 8:e77206

Guo XG, Chavez A, Tung A, Chan Y, Kaas C, Yin Y, Cecchi R, Garnier SL, Kelsic ED, Schubert M et al (2018) High-throughput creation and functional profiling of DNA sequence variant libraries using CRISPR-Cas9 in yeast. Nat Biotechnol 36:540-546 
Haapaniemi E, Botla S, Persson J, Schmierer B, Taipale J (2018) CRISPR-Cas9 genome editing induces a p53-mediated DNA damage response. Nat Med 24:927-930

Harrington LB, Burstein D, Chen JS, Paez-Espino D, Ma E, Witte IP, Cofsky JC, Kyrpides NC, Banfield JF, Doudna JA (2018) Programmed DNA destruction by miniature CRISPR-Cas 14 enzymes. Science 362:839-842

Hu JH, Miller SM, Geurts MH, Tang W, Chen L, Sun N, Zeina CM, Gao $X$, Rees HA, Lin Z et al (2018) Evolved Cas9 variants with broad PAM compatibility and high DNA specificity. Nature 556:57-63

Ihry RJ, Worringer KA, Salick MR, Frias E, Ho D, Theriault K, Kommineni S, Chen J, Sondey M, Ye CY et al (2018) p53 inhibits CRISPR-Cas9 engineering in human pluripotent stem cells. Nat Med 24:939-946

Jackson SP, Bartek J (2009) The DNA-damage response in human biology and disease. Nature 461:1071-1078

Jinek M, Chylinski K, Fonfara I, Hauer M, Doudna JA, Charpentier E (2012) A programmable dual-RNA-guided DNA endonuclease in adaptive bacterial immunity. Science 337:816-821

Kang J, Bronson RT, Xu Y (2002) Targeted disruption of NBS1 reveals its roles in mouse development and DNA repair. EMBO J 21:1447-1455

Kim J, Yu LL, Chen WC, Xu YX, Wu M, Todorova D, Tang QS, Feng BB, Jiang L, He JJ et al (2019) Wild-type p53 promotes cancer metabolic switch by inducing PUMA-dependent suppression of oxidative phosphorylation. Cancer Cell 35:191-203

Komor AC, Badran AH, Liu DR (2017) CRISPR-based technologies for the manipulation of eukaryotic genomes. Cell 168:20-36

Kosicki M, Tomberg K, Bradley A (2018) Repair of double-strand breaks induced by CRISPR-Cas9 leads to large deletions and complex rearrangements. Nat Biotechnol 36:765-771

Lei L, Chen H, Xue W, Yang B, Hu B, Wei J, Wang L, Cui Y, Li W, Wang $J$ et al (2018) APOBEC3 induces mutations during repair of CRISPR-Cas9-generated DNA breaks. Nat Struct Mol Biol 25:45-52

Lin T, Chao C, Saito S, Mazur SJ, Murphy ME, Appella E, Xu Y (2005) p53 induces differentiation of mouse embryonic stem cells by suppressing Nanog expression. Nat Cell Biol 7:165-171 Epub 2004 Dec 2026
Maeder ML, Linder SJ, Cascio VM, Fu YF, Ho QH, Joung JK (2013) CRISPR RNA-guided activation of endogenous human genes. Nat Methods 10:977-979

Mali P, Esvelt KM, Church GM (2013) Cas9 as a versatile tool for engineering biology. Nat Methods 10:957-963

Mladenov E, lliakis G (2011) Induction and repair of DNA double strand breaks: the increasing spectrum of non-homologous end joining pathways. Mut Res 711:61-72

Murovec J, Pirc Z, Yang B (2017) New variants of CRISPR RNAguided genome editing enzymes. Plant Biotechnol J 15:917-926

Song $\mathrm{H}$, Chung SK, Xu Y (2010) Modeling disease in human ESCs using an efficient BAC-based homologous recombination system. Cell Stem Cell 6:80-89

Tan EP, Li YL, Velasco-Herrera MD, Yusa K, Bradley A (2015) Offtarget assessment of CRISPR-Cas9 guiding RNAs in human iPS and mouse ES cells. Genesis 53:225-236

Uematsu N, Weterings E, Yano K, Morotomi-Yano K, Jakob B, Taucher-Scholz G, Mari PO, van Gent DC, Chen BPC, Chen DJ (2007) Autophosphorylation of DNA-PKCS regulates its dynamics at DNA double-strand breaks. J Cell Biol 177:219-229

Urnov FD (2018) Ctrl-Alt-inDel: genome editing to reprogram a cell in the clinic. Curr Opin Genet Dev 52:48-56

WareJoncas Z, Campbell JM, Martínez-Gálvez G, Gendron WAC, Barry MA, Harris PC, Sussman CR, Ekker SC (2018) Precision gene editing technology and applications in nephrology. Nat Rev Nephrol 14:663-677

Xiong J, Todorova D, Su NY, Kim J, Lee PJ, Shen Z, Briggs SP, Xu Y (2015) Stemness factor Sall4 is required for DNA damage response in embryonic stem cells. J Cell Biol 208:513-520

Zetsche B, Gootenberg Jonathan S, Abudayyeh Omar O, Slaymaker Ian M, Makarova Kira S, Essletzbichler P, Volz Sara E, Joung J, van der Oost J, Regev A et al (2015) Cpf1 Is a single RNA-guided endonuclease of a class 2 CRISPR-Cas system. Cell 163:759771

Zhu J, Ming C, Fu X, Duan YO, Hoang DA, Rutgard J, Zhang RZ, Wang WQ, Hou R, Zhang D et al (2019) Gene and mutation independent therapy via CRISPR-Cas9 mediated cellular reprogramming in rod photoreceptors (vol 27, pg 830, 2017). Cell Res 29:337-337 